\title{
Working from home and the willingness to accept a longer commute
}

\author{
Duco de $\operatorname{Vos}^{1}$ (D) Evert Meijers ${ }^{1}$ (D) $\cdot$ Maarten van $\operatorname{Ham}^{1,2}$ (D)
}

Received: 27 June 2017 / Accepted: 25 June 2018 / Published online: 5 July 2018

(c) The Author(s) 2018

\begin{abstract}
It is generally found that workers are more inclined to accept a job that is located farther away from home if they have the ability to work from home one day a week or more (telecommuting). Such findings inform us about the effectiveness of telecommuting policies that try to alleviate congestion and transport-related emissions, but they also stress that the geography of labour markets is changing due to information technology. We argue that estimates of the effect of working from home on commuting time may be biased because of sorting based on residential- and commuting preferences. In this paper we investigate the relationship between telecommuting and commuting time, controlling for preference-based sorting. We use 7 waves of data from the Dutch Labour Supply Panel and show that on average telecommuters have higher marginal cost of one-way commuting time, compared to non-telecommuters. We estimate the effect of telecommuting on commuting time using a fixed effects approach, and we show that preference-based sorting biases cross-sectional results upwards. This suggests that the bias due to sorting based on residential preferences is strongest. Working from home allows people to accept $5 \%$ longer commuting times on average, and every additional $8 \mathrm{~h}$ of working from home are associated with $3.5 \%$ longer commuting times.
\end{abstract}

JEL Classification R11 $\cdot \mathrm{R} 41 \cdot \mathrm{J} 32$

\section{Introduction}

There is an ongoing debate about the extent to which working from home (also called telecommuting) affects the length of the commute people are willing to accept. Early

$\triangle$ Duco de Vos

d.w.devos@tudelft.nl

1 Faculty of Architecture and the Built Environment, Delft University of Technology, Julianalaan 134, 2628 BL Delft, Netherlands

2 School of Geography and Geosciences, University of St Andrews, Irvine Building, North Street, St Andrews, Fyfe KY16 9AL, Scotland, UK 
interest in the effect of telecommuting on commuting distance and household travel was mainly aimed at establishing whether telecommuting could be an effective policy instrument to alleviate congestion and emissions associated with car use (Salomon 1985; Nilles 1991; Lund and Mokhtarian 1994). Increasingly, attention is being given to the notion that telecommuting also affects the geography of labour markets, for example, by having a positive effect on job accessibility (Muhammad et al. 2008; Van Wee et al. 2013). Understanding the relationship between telecommuting and the length of the commute may thus both inform policies aimed at alleviating congestion and transport-related emissions, and policies that aim to improve the economic performance of cities and regions.

Most empirical work on the effects of working from home on commuting tends to corroborate the intuitive notion that being able to avoid the commute one day in the week makes workers more willing to accept a longer commute on the other days of the week (Jiang 2008; Zhu 2012; Kim et al. 2015). However, estimates for the size of this effect vary across the literature, the set of control variables included differs between studies, and there is little attention for the intensity of telecommuting (the number of days per week/month). Moreover, there is no consensus on a strategy to deal with sources of bias stemming from the fact that commute length and telecommuting are often decided upon simultaneously. While some studies aim to eliminate the positive bias that arises if long commutes influence the decision to telecommute (Jiang 2008; Zhu 2012), there is a lack of attention for preference-based sorting. OLS estimates will be biased downward if workers who dislike commuting, and hence have shorter commutes, might also be more likely to work from home. On the other hand, those who have long commutes may be the ones that value residing in more rural areas, where housing quality is cheaper, and working from home may also be more attractive. The latter type of sorting would bias OLS estimates upward.

The objective of this study is to find out to what extent controlling for preferencebased sorting affects the relationship between telecommuting and the length of the commute. Where earlier research on this subject is largely based on either panel data from specific experiments, or cross-sectional data from large-scale surveys, we use Dutch data from a panel survey, representative of the Dutch working age population, spanning 12 years. In the first part of our analysis we provide evidence that preferences for commuting differ between telecommuters and non-telecommuters by comparing the marginal costs of one-way commuting time (MCC) of both groups. To estimate the MCC we use job search and job mobility models, following the approach of Van Ommeren and Fosgerau (2009). The panel structure of the data then allows us to model commuting time and examine to what extent such individual preferences bias crosssectional results, through preference-based sorting. We do this by comparing OLS estimates of commuting time to the results of a fixed effects model that controls for unobservable time-invariant characteristics of respondents. Finally in the sensitivity analysis we apply an even stricter identification method based on the timing and intensity of telecommuting, we employ two alternative identification methods, and we allow for a nonlinear effect of weekly hours spent working from home. 


\section{Telecommuting and the length of the commute}

\subsection{Theoretical implications of telecommuting}

The potential spatial effects of telecommuting and other ICT activities have been theorized upon for at least 50 years. According to Webber (1963), the observed spatial expansion of market areas during the 1960s due to, inter alia, information flows was indicative of a looming "demise of the city" (Webber 1963, p. 1099). Such visions were generally based on the idea that information and communications technology would eventually substitute face-to-face contact, and have been a recurrent theme in futurist writings on the death of cities, and the death of distance (Toffler 1980; Naisbitt 1994; Cairncross 1997).

In much of the literature, telecommuting is seen as a potential policy instrument to decrease car travel, of which the effectiveness is dependent on the overall effect on travel. In transportation research it is often stressed that telecommuting, and ICT activities in general, may substitute, complement, modify, or neutrally affect travel (Salomon 1985). The notion of complementary travel is based on the idea that telecommuting may induce people to accept jobs over longer distances, making the net travel effects of telecommuting not necessarily negative. Furthermore, it is argued that households have a rather fixed mobility budget, and a decrease in trips for commuting would be substituted by leisure trips, and trips of other household members (De Graaff 2004).

However, the welfare effects of telecommuting may stretch further, because workers that are able to telecommute can expand the geographical areas in which they look for jobs (Van Wee et al. 2013). Basic urban economic models support the intuition that if telecommuters have less commuting trips than non-telecommuters, they bid less for homes closer to the Central Business District (the location of employment), and more for suburban homes (Alonso 1974; Lund and Mokhtarian 1994; Jiang 2008). Rhee (2008) shows that in theory, similar results could be obtained in cities with dispersed employment. In situations with little building restrictions, telecommuting may thus in theory promote residential sprawl in a similar way as the automobile did (Glaeser and Kahn 2004). In settings with strict urban containment policies, and a low elasticity of housing supply, such as the Netherlands (Vermeulen and Rouwendal 2007), possibilities for telecommuting may increasingly enable workers to live in one city and reap the benefits of access to labour in other cities (Muhammad et al. 2008; Van Wee et al. 2013).

In the current work we are predominantly interested in the effect of telecommuting on the geographical scale of labour market areas. Therefore, we focus on the relatively uncontested mechanism by which telecommuting potentially increases the length of one-way commutes, because it allows workers to commute less frequently. We do not take into account the effects of telecommuting on non-commute trips, and travel behaviour of other household members.

\subsection{Empirical issues}

Empirical research on the effects of telecommuting on the length of the commute started in the early 1990s, when personal computers started to become a household 
commodity. In a seminal publication, Nilles (1991) investigates the potential effects of telecommuting on urban sprawl and household travel, using data from a telecommuting experiment with California State workers that spanned 2 years. He concludes that at the time, telecommuting did not (yet) exacerbate urban sprawl, and that it resulted in decreased household travel. He did, however, find that telecommuting was associated with moves farther away from the work location, so his findings did not rule out future telesprawl as a consequence.

Later evidence on the relationship between telecommuting and the length of the commute is somewhat scattered, in part because of different definitions of telecommuting. ${ }^{1}$ In a review of evidence by De Graaff (2004) it is concluded that most studies show a negative relationship between telecommuting and the number of commuting trips, and studies that do investigate the length of the commute find mixed evidence, but do not rule out a positive relationship. Andreev et al. (2010) conclude similarly, and stress that the majority of the literature suffers from problems such as the lack of a universal definition of telecommuting, the external validity of the results, and the absence of theoretical substantiation of the results.

Recent endeavours increasingly pay attention to potential sources of bias that influence the results from observational studies. These sources can be divided into (1) omitted variables, (2) reverse causality, and (3) preference-based sorting. With respect to omitted variables, the advent of large-scale surveys in which questions about telecommuting were asked, made it possible to control for a variety of respondent characteristics, and also made it possible to assess telecommuting across different industries. A notable work in this respect is Kim et al. (2012), who estimated the effect of telecommuting on peripheral living, controlling extensively for household characteristics including income, and job locations. Accounting for wage seems particularly relevant in telecommuting research, because earnings and telecommuting status tend to be correlated (Muhammad et al. 2008).

Jiang (2008, p. 10) provides a clear-cut definition of two other types of bias involved in the relationship between telecommuting and commuting distance, and the direction of these biases: "If [a] longer commute encourages an individual to work from home when allowed, a regression of commute length on telecommuting status will overestimate the effect of telecommuting. On the contrary, telecommuters could be those who feel more pressures from traffic. They would have shorter commutes in the absence of telecommuting opportunities. This unobserved selection will lead to a downward [bias] in the regression estimates". We refer to the first bias he addresses as reverse causality, and to the second as sorting based on commuting preferences.

Commuting time and telecommuting may not only be jointly influenced by commuting preferences, but also by residential preferences. Individuals that prefer rural living, and generally have longer commutes, may have larger or more comfortable houses because housing quality tends to be cheaper away from central business areas (Muth 1969). Assuming that spending time in higher quality housing is more pleasurable than spending time in houses of lower quality (Gubins and Verhoef 2014), we may expect that working from home is more attractive for rural dwellers. With

\footnotetext{
1 Mokhtarian et al. (2005) illustrate that definitions, measurement instruments, sampling, and vested interests affect the quality and utility of data, using telecommuting as a case study.
} 
this type of sorting based on residential preferences, an OLS regression of commuting time on telecommuting status would overestimate the real relationship.

A study in which an attempt is made to overcome the bias from potential reverse causality is done by Zhu (2012). He employs an instrumental variables approach, using the number of phones in a household, and the usage of the internet at home as instruments, argued to influence commuting distance only through the effects on telecommuting. Although the reverse causality bias he refers to should lead to overestimation of the effect of telecommuting, he finds that his IV approach leads to higher estimates, compared to OLS. According to his IV results for the year 2009, telecommuters that work from home at least once a week have a $1576 \%$ longer commuting distance, and a $160 \%$ longer commuting duration on average. ${ }^{2}$ While these estimates are large, the results suggest that the bias not accounted for in OLS models is positive rather than negative.

Jiang (2008) uses a similar IV approach, but the instruments in this study are based on the penetration of home-based teleworking across combinations of occupations and city size classes. The results of this study show that OLS tends to underestimate the real effect of telecommuting. While the OLS estimates in this study show that, at least for married women, telecommuting increases commuting time by $3 \mathrm{~min}$, the IV estimates suggest an effect of 9-11 min. No significant results are found for men, and single women.

The current study addresses several gaps that emerge from the literature. First, next to household characteristics we include detailed job characteristics as control variables, including monthly wage, the type of industry, the type of employment, and the usual number of work days per week. Especially the latter control is a novelty in this type of research. Second, we make use of the time dimension of our data, and we focus on the effect of changes in telecommuting status, on changes in commuting time. ${ }^{3}$ Arguably, this makes the potential bias of reverse causality less pressing. While exogenous changes in commuting time (for instance due to firm relocations) may influence the decision to telecommute, this still indicates that telecommuting increases the willingness to accept a longer commute. Finally, the time dimension of the data also allows us to control for all time-invariant characteristics of respondents through the use of fixed effects models. Such time-invariant characteristics include unobserved commuting- and residential preferences, so this approach allows us to address the bias due to preference-based sorting. This is one of the first studies to address the relationship between telecommuting and commuting distance with a fixed effects approach. $^{4}$

\footnotetext{
2 Given his log-linear model, these are the marginal effects of the telecommuting dummy for which the point estimate is 2.819 for the distance model, and 0.993 for the duration model. The marginal effects are calculated as $\left(e^{\beta}-1\right) * 100 \%$. The corresponding marginal effects of his OLS estimates are more realistic: 23 and $19 \%$, respectively.

3 The fixed effects models use variation in telecommuting within individuals, over time, to explain timevariation in commuting time within individuals.

4 Two notable studies that apply a fixed effects to approach to telecommuting research are De Graaff (2004), who looks at the relationship between telecommuting and total travel, and Kolko (2012), who aims to uncover how broadband availability affects the adoption of telecommuting.
} 


\section{Data and methods}

\subsection{Data description}

Our empirical analyses are based on data from the Netherlands. The urban landscape of the Netherlands is characterized by a polycentric urban structure with many smalland medium-sized cities. Labour- and housing markets stretch far beyond cities, and it is relatively common to live in or near one city, and work in another urban area (Burger and Meijers 2016). Another notable characteristic is the concentration of employment in the Randstad area, in the west of the country. This area is also characterized by a higher wage level (Groot et al. 2014), and better matching between workers and employers indicated by lower levels of overeducation (Büchel and Van Ham 2003). In the Netherlands telecommuting is a relatively widespread phenomenon, due to the mass adoption of ICT, the high share of the tertiary sector in economic activities, and the high population density and the associated congestion problems (Muhammad et al. 2007, 2008).

The data we use come from the Labour Supply Panel (SCP 2016), and it consists of the 7 latest biannual waves (between 2002 and 2014). While the panel has been running since 1985, 2002 is the first year in which questions were asked about the degree to which people work from home. We have 18,730 observations for 7497 individuals. ${ }^{5}$

\subsection{Telecommuting definition}

We are interested in the relationship between telecommuting and the (accepted) commuting time. As mentioned earlier, a variety of definitions of telecommuting is used in related literature. Mokhtarian et al. (2005) give an overview, starting from the idea that telecommuting involves "salaried employees of an organization [that] replace or modify the commute by working at home or a location closer to home than the regular workplace, generally using ICT [...]" (Mokhtarian et al. 2005, p. 427). Studies from their literature review have threshold values for the intensity of telecommuting that range from at least once per month, to at least once per week.

Two questions from the survey we use relate to the intensity of telecommuting. The first asks to state how many days per month respondents work from home usually. The answers to this question are measured on an ordinal scale with 5 possibilities $(0,1$, 2 , and 3 days, and more than 3 days). The second question asks to state the average number of weekly hours spent from home in the 4 weeks before the survey date, and the resulting variable is measured on a continuous scale. Both questions contain some ambiguities, the first one about what is meant by "usually" and the second one about whether these hours working from home substitute commuting activities. Therefore, our definition of telecommuters will be based on workers who usually work at home

\footnotetext{
5 We excluded extreme observations with commuting times longer than 500 min, monthly wages lower than $€ 500$, and daily wages higher than $€ 1,000$, and following other studies we excluded self-employed workers (Mokhtarian et al 2005; Kim et al 2012).
} 

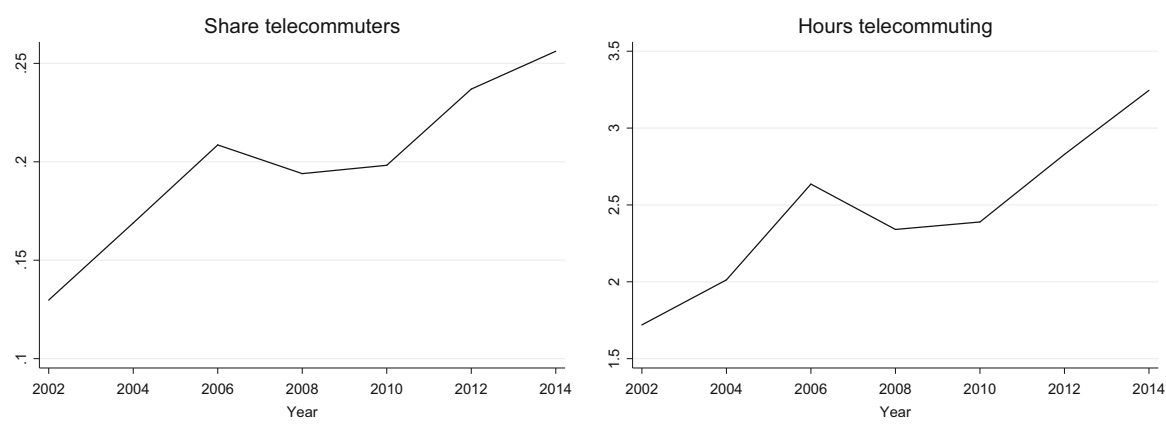

Fig. 1 Time patterns of working from home

at least once per month, and have worked from home at least $4 \mathrm{~h}$ on average during the 4 weeks before the survey date. ${ }^{6}$

Another question asks whether respondents use email or internet to work from home. Limiting our sample to salaried employees, our data thus allow us to define telecommuting as workers who work regularly from home, substituting commuting activities, and using ICT. The only discrepancy with the definition of Mokhtarian et al. (2005) involves workers who telecommute from a location closer to home than the regular workplace. To the extent that we still measure telecommuting with an error, our estimates will be biased towards zero.

We will perform our analyses using (1) a dummy that indicates whether or not a respondent telecommutes, (2) an ordinal factor variable that denotes the usual number of telecommuting days per month, and (3) a continuous measure of the average weekly hours working from home (for telecommuters). Figure 1 shows the time patterns of the share of telecommuters, and the average weekly hours working from home. Both graphs show an increase in telecommuting (intensity) between 2002 and 2014, with a dip in the years 2008 and $2010 .^{7}$ The overall increasing pattern stresses that telecommuting is still a dynamic and upcoming trend.

\subsection{Other variables and summary statistics}

Commuting time is measured as the usual time it takes to get to work from the residential location. The data does not contain information on commuting distance. However, modelling commuting distance is generally plagued by assumptions about mode choice and commuting speed (Isacsson et al. 2013), while the use of commuting time can be justified by the assumption that commuting speed is optimally chosen (Van Ommeren and Fosgerau 2009).

Figure 2 shows the (kernel) distribution of one-way commuting time for nontelecommuters, occasional telecommuters (up to 3 days per month), and regular

\footnotetext{
6 The $4 \mathrm{~h}$ on average per week are chosen to come close to a threshold value of 2 telecommuting days per month, which holds the middle ground between the threshold values mentioned in Mokhtarian et al (2005).

7 Data from the US Community Survey show a similar dip in working from home around 2008, and in the popular press this dip is often attributed to the Great Recession (see http://www.bbc.com/news/business-1 9594518).
} 


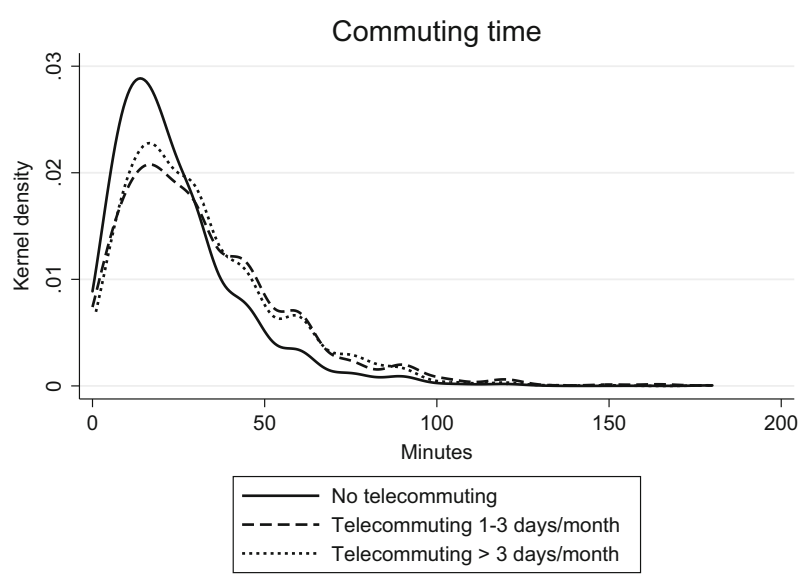

Fig. 2 Distribution of commuting time according to telecommuting status. The density functions are estimated with a Gaussian kernel, and a bandwidth of 5 min

Table 1 Telecommuting and changes in commuting time

\begin{tabular}{lrcc}
\hline & $N$ & Mean change & SD \\
\hline $\begin{array}{c}\text { Started telecommuting } \\
\text { between } t-2 \text { and } t\end{array}$ & 975 & 1.494 & 17.358 \\
No change & 9554 & 0.307 & 14.377 \\
$\begin{array}{l}\text { Quit telecommuting } \\
\text { between } t-2 \text { and } t\end{array}$ & 704 & -0.652 & 19.885 \\
\hline
\end{tabular}

telecommuters (more than 3 days per month). The figure shows that the distribution of commuting times for non-telecommuters has its bulk between 0 and $25 \mathrm{~min}$, while the distributions of the other categories are more spread, including relatively longer commutes. The average commuting time for non-telecommuters is $24 \mathrm{~min}$, versus $32 \mathrm{~min}$ for occasional telecommuters, and $31 \mathrm{~min}$ for regular telecommuters. So far, it seems that non-telecommuters have considerably shorter commutes on average, while regular telecommuters do not have longer commuting times than occasional telecommuters.

In Table 1 we make use of the time dimension of our data, and a similar pattern emerges. Commuting times of respondents who started to telecommute between two consecutive waves increased by $1.5 \mathrm{~min}$ on average, while the average increase is 0.31 for respondents for whom nothing changed, and average commuting times decreased for respondents that quit telecommuting. ${ }^{8}$

Other essential variables are all deduced from answers to questions in the survey: we calculate the daily wage of respondents based on the (stated) net wage per month and the usual number of working days per week, assuming 6 weeks of vacation on average; job search is measured as a dummy indicating the respondent is searching for a job at the moment the survey was conducted; job mobility is measured as a dummy that indicates whether or not the respondent changed jobs between two consecutive survey waves, and in our analysis we use the 2-year lead of this variable.

\footnotetext{
${ }^{8} T$ tests confirm that differences between these groups are significant at the $5 \%$ confidence level.
} 
Table 2 shows the summary statistics of variables used in our analyses, including the average number of working days per week, firm sector and size, age, sex, the presence of children and a partner, and the wage of the partner.

\subsection{Methods}

We introduced two types of preference-based sorting that may bias OLS results: sorting based on commuting preferences and sorting based on residential preferences. Our data allow us to investigate whether commuting preferences significantly differ between telecommuters and non-telecommuters. In the first part of our empirical analysis therefore, we use a model based on job search theory to calculate the marginal monetary value of one-way commuting time (MCC) both for both groups separately. If the MCC is significantly higher for telecommuters, we interpret this as evidence for sorting based on commuting preferences.

Using the job search approach we relate commuting time and wage levels with each other through their effects on (1) on-the-job search, and (2) job mobility (Van Ommeren and Fosgerau 2009). The intuition behind this approach is that workers are not in their preferred job per se, and are able to improve upon their situation by searching for jobs, and moving jobs if they find a better fit that improves their lifetime utility (Van Ommeren et al. 2000). By calculating the effect of commuting time on job search and job moving, we get an indication of the willingness to accept longer commuting times. Moreover, by calculating the ratio of the effect of commuting time and the effect of wages, we can put a monetary value on this willingness to accept (Van Ommeren and Fosgerau 2009). The advantage of this approach is that we do not need to assume that labour markets are in equilibrium (Gronberg and Reed 1994). In other words, we do not need to assume that observed situations in the labour market reflect the best choices among all available alternatives.

Conceptually, our regression model distinguishes between telecommuting as a job asset, and telecommuting as a substitute for commuting physically. We investigate the effect of telecommuting on the acceptability of one-way commuting times by examining the interactions between a telecommuting dummy and commuting distance. The main effect of this telecommuting dummy tells us something about the intrinsic value of telecommuting. Several studies suggest for instance that working from home on designated, individual tasks may increase worker productivity (Bernardino 2017). Furthermore, the possibility to telecommute may increase the chance of matching between workers and employers if labour markets for telecommuting jobs indeed have a larger geographical scale.

In the second part of the analysis, we estimate the extent and direction of sorting bias. We compare the outcomes of an OLS commuting time regression to the results from an individual fixed effects approach that makes use of the panel dimension of the data. The latter method corrects for all time-invariant characteristics of people, including time-constant preferences. We control for time-variant confounders as much as possible by accounting for (changes in) monthly wage, the industry in which people work, the type of employment, whether or not individuals have a partner or kids at home, and the wage of the partner. 
Table 2 Summary statistics of full sample

\begin{tabular}{|c|c|c|c|c|c|}
\hline Variables & $N$ & Mean & SD & Min. & Max. \\
\hline Telecommuting & 18,730 & 0.2 & 0.4 & 0 & 1 \\
\hline Telecommuting 0 days/month & 18,730 & 0.681 & 0.466 & 0 & 1 \\
\hline Telecommuting 1 day/month & 18,730 & 0.0984 & 0.298 & 0 & 1 \\
\hline Telecommuting 2 days/month & 18,730 & 0.0758 & 0.265 & 0 & 1 \\
\hline Telecommuting 3 days/month & 18,730 & 0.0753 & 0.264 & 0 & 1 \\
\hline $\begin{array}{l}\text { Telecommuting } \\
>3 \text { days/month }\end{array}$ & 18,730 & 0.0698 & 0.255 & 0 & 1 \\
\hline Telecommuting weekly hours & 18,730 & 2.467 & 6.803 & 0 & 97 \\
\hline Commuting time & 18,730 & 26.81 & 21.07 & 0 & 180 \\
\hline Job search at t & 18,730 & 0.114 & 0.317 & 0 & 1 \\
\hline Job move between $t-2$ and $t$ & 18,730 & 0.154 & 0.361 & 0 & 1 \\
\hline Job move between $t$ and $t+2$ & 11,320 & 0.104 & 0.306 & 0 & 1 \\
\hline Daily wage & 18,730 & 106.5 & 44.76 & 21.06 & 808.7 \\
\hline Monthly wage & 18,730 & 1.742 & 791.9 & 501 & 16,667 \\
\hline Working days/week & 18,730 & 4.323 & 0.965 & 1 & 7 \\
\hline Firm size & 18,730 & 613.2 & 2.446 & 0 & 70,000 \\
\hline Age & 18,730 & 43.11 & 11.04 & 16 & 66 \\
\hline Female & 18,730 & 0.468 & 0.499 & 0 & 1 \\
\hline Partner & 18,730 & 0.798 & 0.402 & 0 & 1 \\
\hline Partner wage & 18,730 & 1.148 & 2.567 & 0 & 75,000 \\
\hline Children at home & 18,730 & 0.571 & 0.495 & 0 & 1 \\
\hline Primary education & 18,730 & 0.0153 & 0.123 & 0 & 1 \\
\hline Basic education & 18,730 & 0.189 & 0.392 & 0 & 1 \\
\hline Higher education & 18,730 & 0.38 & 0.485 & 0 & 1 \\
\hline Vocational education & 18,730 & 0.29 & 0.454 & 0 & 1 \\
\hline Bachelor degree & 18,730 & 0.125 & 0.331 & 0 & 1 \\
\hline Sector: agriculture & 18,730 & 0.00769 & 0.0873 & 0 & 1 \\
\hline Sector: industry & 18,730 & 0.122 & 0.327 & 0 & 1 \\
\hline Sector: construction & 18,730 & 0.041 & 0.198 & 0 & 1 \\
\hline Sector: trade & 18,730 & 0.122 & 0.328 & 0 & 1 \\
\hline Sector: transport & 18,730 & 0.0569 & 0.232 & 0 & 1 \\
\hline Sector: business services & 18,730 & 0.178 & 0.382 & 0 & 1 \\
\hline Sector: healthcare & 18,730 & 0.204 & 0.403 & 0 & 1 \\
\hline Sector: other & 18,730 & 0.0456 & 0.209 & 0 & 1 \\
\hline Sector: government & 18,730 & 0.107 & 0.309 & 0 & 1 \\
\hline Sector: education & 18,730 & 0.117 & 0.321 & 0 & 1 \\
\hline Job type: civil servant & 18,730 & 0.191 & 0.393 & 0 & 1 \\
\hline Job type: employee & 18,730 & 0.8 & 0.4 & 0 & 1 \\
\hline Job type: director & 18,730 & 0.00892 & 0.094 & 0 & 1 \\
\hline
\end{tabular}



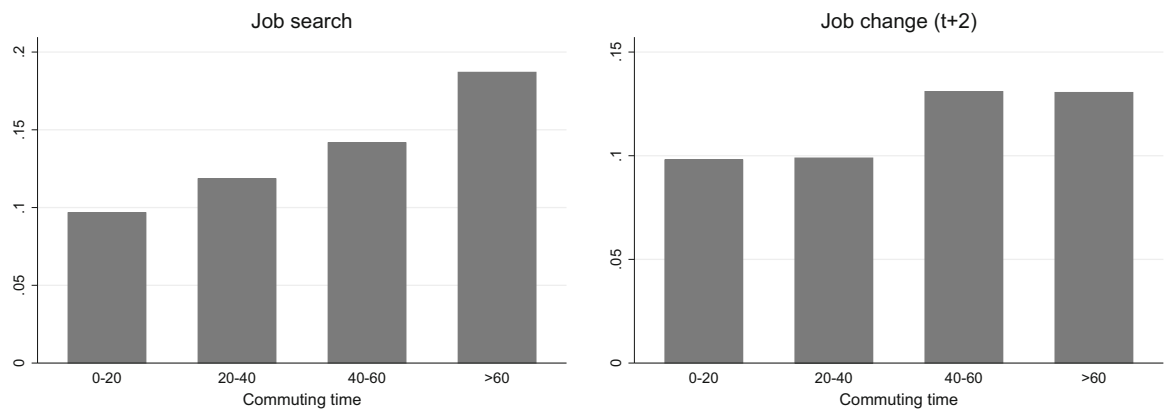

Fig. 3 Bivariate relationships between commuting time and job search (1), and job mobility (r)

\section{Results}

\subsection{Evidence for preference-based sorting}

In this subsection we examine the difference in commuting preferences between telecommuters and non-telecommuters. We do this by estimating the effect of commuting time on job search and the propensity to change jobs, for both groups. We standardize this effect by the effects of wage on job search and mobility to obtain the marginal costs of one-way commuting time (MCC), measured as the average amount of daily wage people are willing to give up to shorten their (one-way) commute with 1 min (Van Ommeren and Fosgerau 2009). First, in Fig. 3 we show the bivariate relationship between commuting time and job search and mobility for the whole sample. It is clear that both the share of people looking for a job and the share of people changing jobs within 2 years are positively related with commuting time. This confirms the intuitive notion that longer commutes are seen as a negative aspect of jobs. ${ }^{9}$

In Table 3 we estimate the daily MCC using the two distinct approaches. We follow the literature and use a random effects probit model to deal with potential heterogeneity among different individuals. ${ }^{10}$ According to the job search model in column (1) commuting time has a greater effect on job search for telecommuters than for nontelecommuters. In monetary terms, non-telecommuters are willing to accept a $1 \mathrm{~min}$ longer one-way commute for $€ 2.63$ per work day, while telecommuters are willing to accept a 1 min longer commute for $€ 3.80 .{ }^{11}$ Note that this is in spite of the fact that, by definition, telecommuters commute less frequently, compared to non-telecommuters, so the MCC per commuting trip may be even higher for telecommuters. Furthermore, according to this model age has a positive but marginally decreasing effect on the propensity to search, and higher educated people search more. The effect of telecommuting itself is insignificant.

In column (2) we estimate the same model with job mobility (changing jobs within 2 years) as the dependent variable. According to this model the MCC is $€ 1.91$ for

\footnotetext{
${ }^{9}$ We found no such clear bivariate patterns between telecommuting and job search and mobility.

10 This allows the error terms of the same individuals to be correlated over time (Van Ommeren and Fosgerau 2009).

11 The MCC is derived from the ratio of the effects of commuting time and daily wage.
} 
Table 3 Willingness to pay for commuting regressions

\begin{tabular}{|c|c|c|}
\hline & $\begin{array}{l}\text { (1) } \\
\text { Job search }\end{array}$ & $\begin{array}{l}\text { (2) } \\
\text { Job mobility }\end{array}$ \\
\hline Commute $*$ no telecommuting & $\begin{array}{l}0.00494 * * * \\
(0.000927)\end{array}$ & $\begin{array}{l}0.00330^{* * *} \\
(0.00117)\end{array}$ \\
\hline Commute $*$ telecommuting & $\begin{array}{l}0.00712 * * * \\
(0.00128)\end{array}$ & $\begin{array}{l}0.00372^{* *} \\
(0.00155)\end{array}$ \\
\hline Telecommuting & $\begin{array}{l}-0.0597 \\
(0.0671)\end{array}$ & $\begin{array}{l}0.112 \\
(0.0824)\end{array}$ \\
\hline Daily wage & $\begin{array}{l}-0.00187 * * * \\
(0.000545)\end{array}$ & $\begin{array}{l}-0.00172 * * \\
(0.000787)\end{array}$ \\
\hline Firm size & $\begin{array}{l}4.75 e-06 \\
(6.12 e-06)\end{array}$ & $\begin{array}{l}-2.89 \mathrm{e}-05 \\
(1.77 \mathrm{e}-05)\end{array}$ \\
\hline Age & $\begin{array}{l}0.0755^{* * *} \\
(0.0131)\end{array}$ & $\begin{array}{l}-0.0320 * \\
(0.0170)\end{array}$ \\
\hline $\mathrm{Age}^{2}$ & $\begin{array}{l}-0.00114 * * * \\
(0.000157)\end{array}$ & $\begin{array}{l}3.01 \mathrm{e}-05 \\
(0.000207)\end{array}$ \\
\hline Female & $\begin{array}{l}0.0263 \\
(0.0441)\end{array}$ & $\begin{array}{l}-0.0954^{*} \\
(0.0570)\end{array}$ \\
\hline Partner & $\begin{array}{l}-0.217 * * * \\
(0.0475)\end{array}$ & $\begin{array}{l}-0.177 * * * \\
(0.0610)\end{array}$ \\
\hline Partner wage & $\begin{array}{c}-5.59 \mathrm{e}-06 \\
(6.71 \mathrm{e}-06)\end{array}$ & $\begin{array}{l}1.58 \mathrm{e}-05^{* *} \\
(6.96 \mathrm{e}-06)\end{array}$ \\
\hline Children at home & $\begin{array}{l}0.0130 \\
(0.0424)\end{array}$ & $\begin{array}{l}0.0329 \\
(0.0533)\end{array}$ \\
\hline Basic education & $\begin{array}{l}-0.0764 \\
(0.152)\end{array}$ & $\begin{array}{l}-0.0290 \\
(0.160)\end{array}$ \\
\hline Higher education & $\begin{array}{l}0.0201 \\
(0.151)\end{array}$ & $\begin{array}{l}0.00369 \\
(0.158)\end{array}$ \\
\hline Vocational education & $\begin{array}{l}0.279 * \\
(0.154)\end{array}$ & $\begin{array}{l}0.166 \\
(0.162)\end{array}$ \\
\hline Bachelor degree & $\begin{array}{l}0.449 * * * \\
(0.160)\end{array}$ & $\begin{array}{l}0.210 \\
(0.172)\end{array}$ \\
\hline Constant & $\begin{array}{l}-1.841^{* * * *} \\
(0.389)\end{array}$ & $\begin{array}{l}0.703 \\
(0.567)\end{array}$ \\
\hline Individual random effects & Yes & Yes \\
\hline Year dummies & Yes & Yes \\
\hline Control dummies & Yes & Yes \\
\hline Observations & 18,730 & 11,320 \\
\hline Individuals & 7497 & 4481 \\
\hline Rho & 0.335 & 0.243 \\
\hline
\end{tabular}


Table 3 continued

\begin{tabular}{lll}
\hline & $(1)$ & $(2)$ \\
& Job search & Job mobility \\
\hline Log likelihood & -6136 & -3493 \\
MCC non-telecommuters & $€ 2.63$ & $€ 1.91$ \\
MCC telecommuters & $€ 3.80$ & $€ 2.15$ \\
Relative difference & 1.44 & 1.13 \\
\hline
\end{tabular}

Robust std. errors in parentheses. Control dummies include 7 working days-, 10 industry-, and 5 job type dummies. MCC stands for marginal cost of commuting, and should be interpreted as the daily willingnessto-pay for a $1 \mathrm{~min}$ reduction in one-way commuting time

$* * * p<0.01 ; * * p<0.05 ; * p<0.1$

non-telecommuters, and $€ 2.15$ for telecommuters. These values are lower than the estimates in the previous model. The ratio between these values is also lower (1.13 vs. 1.44). According to this model the effect of age on mobility is predominantly negative, and higher educated people seem more mobile, but not significantly so. The effect of telecommuting itself on job moving is not significant.

In conclusion, this part of the analysis shows that the MCC is between 13 and $44 \%$ higher on average for telecommuters, in spite of the fact that their commuting frequency is lower. Therefore, it is established that preferences of telecommuters differ significantly from non-telecommuters in terms of commuting tolerance. More specifically, if there was only sorting based on commuting preferences, not taking into account these preferences when analyzing the effect of telecommuting on commuting time would lead to underestimation of the real effect. We find no evidence that telecommuting is a positive job asset in itself.

\subsection{Commuting time}

In this subsection we estimate the effect of telecommuting on commuting time, controlling for preference-based sorting by employing individual fixed effects. We start with an OLS model, and we compare the resulting estimates with the results of a fixed effects model. Because the dependent variable is in logs, 187 observations with 0 commuting time are excluded from the analysis, so we are left with 18,543 observations.

Table 4 shows the OLS results. In column (1) we use a telecommuting dummy that corresponds to our telecommuting definition. According to this model telecommuting results in a $11.7 \%$ longer commute on average. ${ }^{12}$ Furthermore, a $10 \%$ increase in daily wage is associated with a $4.8 \%$ increase in commuting time, the level of education has a positive effect on commuting time, commuting patterns are gendered (women have about $7.6 \%$ shorter commutes), and individuals with children at home have about $7 \%$ shorter commutes. Except for the insignificant effect of age, these findings are in line with earlier results on Dutch commuting behaviour, which showed that females, and people with children, have shorter commutes on average, and people of higher socio-

\footnotetext{
12 The coefficients in these log-linear models should be interpreted as an $\left(e^{\beta}-1\right) * 100 \%$ increase for every unit increase. For logged independent variables the coefficients can be interpreted as an elasticity.
} 
Table 4 OLS commuting time regressions

(1)

$0.111 * * *$

Telecommuting

Telecommuting 1 day/month

Telecommuting 2 days/month

Telecommuting 3 days/month

Telecommuting $>3$ days/month

Telecommuting weekly hours

Daily wage (log)

Firm size

Age

Age $^{2}$

Female

Partner

Partner wage

Children at home

Basic education

Higher education

Vocational education

Bachelor degree

Constant

Year dummies

Control dummies

(0.0164)

(0.0213)

(0.0150)

(0.0162)

(0.0139)

0.0223

(0.0477)

$0.115 * *$

(0.0471)

$0.172 * * *$

(0.0483)

$0.259 * * *$

(0.0508)

(0.179)

$$
\begin{aligned}
& 0.0308 \\
& (0.0229) \\
& 0.163 * * * \\
& (0.0226) \\
& 0.0982 * * * \\
& (0.0217) \\
& 0.0568 * * \\
& (0.0231)
\end{aligned}
$$

$0.00636^{* * * *}$

(0.00126)

$0.487 * * *$

(0.0211)

$0.479 * * *$

$1.79 \mathrm{e}-05^{* * * *}$

$1.81 \mathrm{e}-05^{* * * *}$

(0.0214)

(2.93e-06)

(2.93e-06)

$1.82 \mathrm{e}-05 * * *$

$-0.00376$

$(0.00455)$

$-0.00441$

(0.00455)

$2.47 \mathrm{e}-05$

(5.34e-05)

(0.00455)

$2.28 \mathrm{e}-05$

$3.10 \mathrm{e}-05$

$(5.34 \mathrm{e}-05)$

$-0.0728 * * *$

$(5.35 \mathrm{e}-05)$

$-0.0738 * * *$

$-0.00568$

$-3.24 \mathrm{e}-06$

$-0.0725^{* * *}$

(0.0150)

(0.0150)

$-0.00502$

(0.0162)

$-3.24 \mathrm{e}-06$

(2.47e-06)

$-0.0674 * * *$

(0.0162)

(2.48e-06)

(2.49e-06)

$-0.0660 * * *$

$-0.0669 * * *$

(0.0140)

0.0217

(0.0477)

$0.117 * *$

(0.0471)

$0.178 * * *$

(0.0483)

$0.268 * * *$

(0.0508)

$-0.0597$

(0.178)

0.00857

Yes

Yes

Yes 
Table 4 continued

\begin{tabular}{llll}
\hline & $(1)$ & $(2)$ & $(3)$ \\
\hline Observations & 18,543 & 18,543 & 18,543 \\
$R$-squared & 0.132 & 0.132 & 0.132 \\
\hline
\end{tabular}

Dependent variable: commuting time (log). Robust std. errors in parentheses. In columns (1) and (2) no telecommuting is the reference category. Control dummies include 7 working days-, 10 industry-, and 5 job type dummies

$* * * p<0.01 ; * * p<0.05 ; * p<0.1$

economic status commute longer (Van Ham 2002; Burger et al. 2014). Employees of larger firms commute longer according to this model.

In column (2) we distinguish between 1,2,3, and more than 3 days of telecommuting per month. The results show that the positive effect found in the previous column is mainly driven by telecommuters that telecommute $2-4$ days per month, as the effect of telecommuting 1 day per month is small and insignificant. The coefficients of the other variables are virtually unaffected by this alternative measure of telecommuting. In column (3) we measure telecommuting by the usual number of hours per week spent telecommuting. Arguably this is the most precise measure of telecommuting intensity. According to the model every 8 additional hours of telecommuting lead to a $5.2 \%$ increase in commuting time. The other coefficients are again similar to those in previous models.

In Table 5 we estimate the same models including individual specific fixed effects that correct for all time-invariant attributes of individuals, including preferences. Coefficients are estimated based on variation within individuals over time. The results from column (1) indicate that telecommuting leads to $5 \%$ longer commutes, rather than the $11.7 \%$ estimated in column one. Thus, the extent of the bias due to sorting is positive $(+128 \%)$ according to this specification. The fixed effects model results in several different coefficients compared to the OLS estimates. First, the effect of daily wage on commuting time is lower when accounting for time-invariant unobservables. This may for instance be driven by correlations between capability and labour mobility. Second, it seems that ageing does not significantly influence commuting time. Third, changes in firm size and having children at home have significant but smaller effects on commuting time, compared to the OLS model. Finally, while we see an increasing pattern in the effects of education on commuting, the estimates are not significant.

Column (2) is the fixed effects equivalent of Table 4, column (2). The results from this column show that compared to non-telecommuters, individuals that telecommute 1 day per month accept a $6.1 \%$ longer commute, those telecommuting 2 days per month a similar but lower $5.1 \%$, those that telecommute 3 days do not have significantly longer commutes. This result is somewhat counter-intuitive as it suggests positive but decreasing effect of telecommuting on commuting time. It should, however, be noted that the only significant difference in coefficients between consecutive categories is the one between no telecommuting and telecommuting 1 day per month. Other coefficients in this model are similar to those in the previous column.

Finally, in column (3) we estimate the effect of (changes in) the usual weekly hours spent telecommuting on (changes in) commuting time. The effect is estimated at a 
Table 5 FE commuting time regressions

(1)

$0.0486 * * *$

Telecommuting

(0.0141)

Telecommuting 1 day/month

Telecommuting 2 days/month

Telecommuting 3 days/month

Telecommuting $>3$ days/month

Telecommuting weekly hours

Daily wage (log)

Firm size

Age

Age $^{2}$

Partner

Partner wage

Children at home

Basic education

Higher education

Vocational education

Bachelor degree

Indiv. fixed effects

Year dummies

Control dummies
(2)

(3)
$0.00425 * * *$

(0.000827)

$0.176 * * *$

(0.0269)

$5.28 \mathrm{e}-06^{* * *}$

(2.13e-06)

0.00558

(0.00745)

$2.94 \mathrm{e}-05$

(7.98e-05)

$0.0952 * * *$

(0.0276)

$2.99 \mathrm{e}-07$

(1.82e-06)

$-0.0389 * *$

(0.0175)

0.0644

(0.0576)

0.0686

(0.0600)

0.0810

(0.0640)

0.114

(0.0715)

Yes

Yes

Yes 
Table 5 continued

\begin{tabular}{llll}
\hline & $(1)$ & $(2)$ & $(3)$ \\
\hline Observations & 15,505 & 15,505 & 15,505 \\
$R$-squared & 0.797 & 0.797 & 0.797 \\
\hline
\end{tabular}

Dependent variable: commuting time (log). Robust std. errors in parentheses. In columns (1) and (2) no telecommuting is the reference category. Control dummies include 7 working days-, 10 industry-, and 5 job type dummies

$* * * p<0.01 ; * * p<0.05 ; * p<0.1$

$3.5 \%$ increase in commuting time for every 8 additional weekly hours spent working at home, indicating a $50 \%$ upward bias due to preference-based sorting in the OLS estimate in column (3), Table 4.

From the analyses in this subsection we conclude that telecommuting significantly affects commuting time and overall, the bias induced by preference-based sorting of individuals into telecommuting is positive rather than negative, between 50 and $128 \% .{ }^{13}$ An explanation for this may be that overall, the (negative) bias induced by residential preferences is stronger than the (positive) bias due to commuting preferences. According to our results telecommuting allows people to accept 5\% longer commutes on average, and for every 8 additional weekly hours spent working from home, people accept a $3.5 \%$ longer commute.

\subsection{Sensitivity analysis}

In this subsection we subject our results to several sensitivity checks. We employ a stricter identification approach based on the timing and intensity of telecommuting, and two alternative identification approaches using a Lagged Dependent Variable Model and a Long Difference model.

First, we analyze individuals that telecommuted at some point during the study period. For these individuals we know that they are able to telecommute, so the decision of whether or not to telecommute, and for how many days and hours, suffers less from potentially omitted variables and self-selection. The drawback of this approach is that the external validity of the results is limited, because the effects we obtain in principle only apply to those able to telecommute. The results of these timing regressions, presented in Table 6, "Appendix A", are comparable to the estimates from Table 5.

Second, we use an identification method based on a lagged dependent variable, proposed by Angrist and Pischke (2008) as a robustness check for fixed effects models. Specifically, instead of assuming that telecommuting is randomly assigned across respondents conditional on unobserved time-invariant characteristics, this method assumes random assignment conditional on the 1 year lag of commuting distance. Checking the robustness of our results to this assumption makes sense because commuting time is time-varying, and those who start to telecommute may do so because

13 The models with a telecommuting dummy suggest a $128 \%$ bias [0.0486 (FE) vs. 0.111 (OLS)], and the models with a continuous measure of weekly hours spent working from home suggest a 50\% bias [0.00425 (FE) vs. $0.00636(\mathrm{OLS})]$. 
over time, they have become tired of their long commute. This method thus corrects for a different type of selection bias (based on commuting history), and as Angrist and Pischke (2008) note, the results of fixed effects and lagged dependent variable models can be regarded as bounding the effect of interest, depending on the type of selection bias that is controlled for. In Table 7 we show the results of the models based on this identification strategy, and it is reassuring that the outcomes of this analysis are remarkably similar to the estimates from Table 5.

Third, we estimate a "long-differences" model in which we only include the first and last year of our data, controlling for time-invariant characteristics of respondents. This approach is only based on 516 respondents for whom we have data for both years. The idea behind this robustness check is that it takes time to get used to new technologies and situations, and to adjust behaviour in housing and labour markets. The results, presented in Table 8, suggest that our estimates based on short-run behaviour may be somewhat conservative. Respondents that have picked up telecommuting between 2002 and 2014 have on average 32\% longer commuting times, and every $8 \mathrm{~h}$ increase in weekly telecommuting hours during this period resulted in $20.5 \%$ longer commuting times. It should, however, not be ruled out that these high estimates are the result of sample selection effect: respondents with high residential mobility are less likely to be contacted over multiple years, but they are more prone to shorten their commutes by moving residence (Van Ommeren 1998).

Finally, we investigate whether there are nonlinearities in the effect of hours working from home on commuting time. We do this by estimating a dummy specification, in which the variable denoting weekly hours spent working from home is divided up into 7 categories $(0,0-8,8-16,16-24,42-32,32-40$, and 40+). The model, presented in the column (1) of Table 9 in "Appendix A", is an alternative version of Table 5 column (3), and the marginal effects of the dummies are depicted in Fig. 4. While the graph does not show significant effects of telecommuting categories 16-24 and 32-40, the overall pattern of point estimates follows a somewhat linear pattern, at least up until the 24-32 h mark. Considering the observed pattern, and the significance of the other dummies, we may conclude that the parametric approach in Table 5 column (3) is a reasonable approximation of the nonparametrically estimated shape of the relationship, and as it is more efficient it has our preference. In Table 9 columns (2-4) we show the results of this dummy specification using the other identification strategies, and in all specifications the pattern is roughly linear until 24-32 h.

In conclusion, the main result - that the effect of telecommuting on commuting time remains positive after controlling for sorting - is robust to identification based on the timing and intensity of telecommuting, and to an identification strategy based on a lagged dependent variable. A "long-difference" model suggests our estimates are somewhat conservative, and a linear specification of average weekly hours working from home is not problematic.

\section{Conclusion}

This paper shows that the relationship between telecommuting and commuting time suffers from a bias due to sorting based on residential- and commuting preferences 


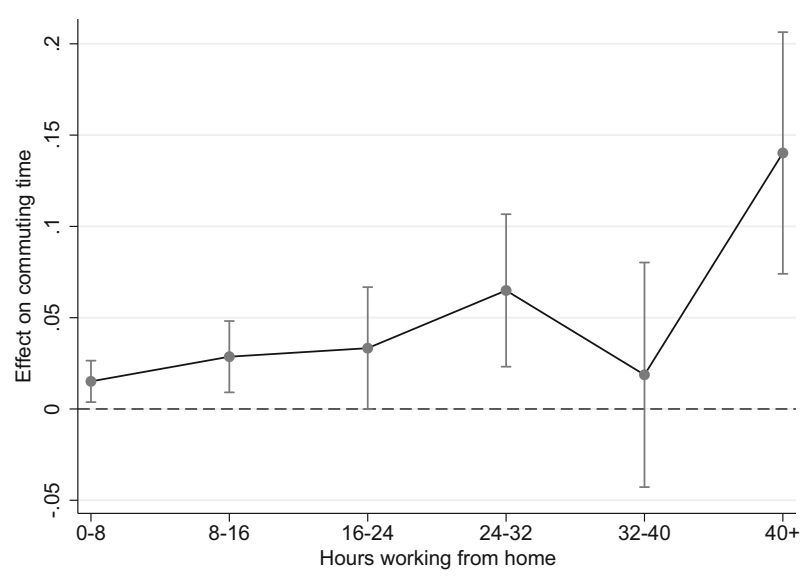

Fig. 4 Nonlinear effect of hours working from home. No telecommuting is the reference category. The dots represent the point estimates, the vertical lines represent the 95\% confidence intervals, and the dashed horizontal line represents zero

that should be accounted for. On the one hand, the effects of commuting time on labour search and labour mobility suggest that telecommuters have a higher value of oneway commuting time, despite their lower commuting frequency, which would lead to a downward bias in OLS estimates of the effect of telecommuting on commuting time. However, using fixed effects to control for (stationary) preferences of individuals, our analysis shows that OLS estimates are biased upward in the range of 50-128\%. This suggests that both residential- and commuting preferences distort OLS findings, and that the bias due to residential sorting is stronger.

Our preferred estimates suggest that moving from a situation with no telecommuting, telecommuting allows people to accept 5\% longer commuting times on average, and every additional 8 weekly hours of working from home are associated with $3.5 \%$ longer commuting times. The main result of this study is that the effect of telecommuting on commuting time remains positive and significant, after controlling for individual preferences. This result is robust to a number of sensitivity checks in which we apply alternative identification methods, and allow for a nonlinear effect of weekly hours working from home.

There are some limitations to the research approach in this paper that could inspire further research. First, we only analyze commuting time, and not commuting distance, because we lack the proper data. Several studies do investigate the effect of telecommuting on both commuting time and distance, and generally find greater elasticities for distance (Andreev et al. 2010; Zhu 2012). Theoretically, focusing on commuting time, and ignoring commuting distance, is justified by assuming that commuting speed is optimally chosen (Van Ommeren and Fosgerau 2009). Second, while we take into account the effects of self-selection, we ignore the possibility that long commutes trigger telecommuting. We argue that whether or not increases in commuting time trigger telecommuting, or telecommuting triggers longer commutes is irrelevant, because it both entails that telecommuters are willing to accept a longer commute, all else equal. However, future research may be directed at finding instruments for 
changes in telecommuting, unrelated to changes in commuting time to assess the oneway causal effect. Finally, our fixed effects model corrects for the bias induced by preference-based sorting only to the extent that these preferences are time-invariant. We are hopeful that our extensive list of control variables captures remaining changes in these preferences, and we note that including fixed effects may at least capture more of the sorting bias than OLS models.

In line with earlier work, our results suggest that the travel savings made by working one or several days at home are not fully offset by the positive effects on commuting distance alone (Jiang 2008; Andreev et al. 2010; Zhu 2012). Beyond that, this paper stresses the effects of telecommuting on the geographical territory of labour markets. Next to reducing the labour accessibility gap between central and remote areas, telecommuting may also allow the externalities associated with the size of local labour markets, including improved searching and matching and less unfilled vacancies (Moretti 2011), to be increasingly generated across greater geographical areas, and through wider infrastructure networks (Burger and Meijers 2016). Further research may focus on the welfare effects associated with a wider geographical extent of labour markets.

Acknowledgements Funding was provided by Nederlandse Organisatie voor Wetenschappelijk Onderzoek (NL) (Grant No. 452-14-004).

Open Access This article is distributed under the terms of the Creative Commons Attribution 4.0 International License (http://creativecommons.org/licenses/by/4.0/), which permits unrestricted use, distribution, and reproduction in any medium, provided you give appropriate credit to the original author(s) and the source, provide a link to the Creative Commons license, and indicate if changes were made.

\section{Appendix A}

This appendix contains tables with regression results from the sensitivity analysis. Table 6 presents models based on a sample that only consists of telecommuters. Table 7 shows the lagged dependent variable models. Table 8 shows the "long differences" models, and Table 9 shows models in which we allow for a nonlinear specification of weekly telecommuting hours.

Table 6 Sensitivity regressions I: telecommuting sample
(1)
(2)

Telecommuting

Telecommuting 1 day/month

Telecommuting 2 days/month
$0.0453 * * *$

$(0.0148)$

$0.0590 * * *$

(0.0197)

$0.0482 * *$

(0.0200) 
Table 6 continued

(1)

Telecommuting 3 days/month

Telecommuting $>3$ days/month

Telecommuting weekly hours

Indiv. fixed effects

Year dummies

Control variables

Observations

$R$-squared
(2)

(3)

$$
\begin{aligned}
& 0.0311 \\
& (0.0197) \\
& 0.0125 \\
& (0.0199)
\end{aligned}
$$

$0.00407 * * *$

(0.000868)

Yes

Yes

Yes

8309

Robust std. errors in parentheses. In columns (1-2) no telecommuting is the reference category. Control variables are the same as in Tables 4 and 5

$* * * p<0.01 ; * * p<0.05 ; * p<0.1$

Table 7 Sensitivity regressions II: lagged dependent variable

(1)

$0.0526^{* * * *}$

(0.0128)

Telecommuting 1 day/month

Telecommuting 2 days/month

Telecommuting 3 days/month

Telecommuting $>3$ days/month

Telecommuting weekly hours

Commuting time at $t-1(\log )$

Indiv. fixed effects

Year dummies

Control variables

Observations

$R$-squared
0.773

(2)

$0.773 \quad 0.773$


Table 8 Sensitivity regressions III: long differences

\begin{tabular}{llll}
\hline & $(1)$ & $(2)$ & $(3)$ \\
\hline Telecommuting & $0.277^{* * *}$ & & \\
Telecommuting 1 day/month & $(0.0777)$ & $0.224^{* *}$ & $(0.0911)$ \\
& & 0.187 & $(0.121)$ \\
Telecommuting 2 days/month & & $0.234 *$ & $(0.132)$ \\
Telecommuting 3 days/month & & 0.0442 & $(0.00416)$ \\
Telecommuting $>3$ days/month & & $(0.098)$ & Yes \\
Telecommuting weekly hours & & & Yes \\
Indiv. fixed effects & Yes & Yes \\
Year dummies & Yes & Yes & Yes \\
Control variables & Yes & 1032 & 0.767 \\
Observations & 1032 & 0.756 & 1032 \\
\hline -squared & 0.759 & & \\
\hline
\end{tabular}

Robust std. errors in parentheses. In columns (1-2) no telecommuting is the reference category. Control variables are the same as in Tables 4 and 5

$* * * p<0.01 ; * * p<0.05 ; * p<0.1$

Table 9 Sensitivity regressions IV: nonlinear telecommuting hours

\begin{tabular}{lllll}
\hline & $(1)$ & $(2)$ & $(3)$ & $(4)$ \\
\hline Telecommuting weekly hours $0-8$ & $0.0348 * * *$ & $0.0349 * *$ & $0.0375^{* *}$ & 0.115 \\
Telecommuting weekly hours 8-16 & $(0.0133)$ & $(0.0150)$ & $(0.0176)$ & $(0.0743)$ \\
Telecommuting weekly hours 16-24 & $0.0659 * * *$ & $0.0609 * *$ & $0.0841^{* * *}$ & $0.317 * * *$ \\
Telecommuting weekly hours 24-32 & $(0.0230)$ & $(0.0260)$ & $(0.0310)$ & $(0.119)$ \\
Telecommuting weekly hours 32-40 & $0.0767 *$ & 0.0696 & 0.0773 & $0.627 * * *$ \\
Telecommuting weekly hours 40+ & $(0.0393)$ & $(0.0426)$ & $(0.0534)$ & $(0.225)$ \\
Commuting time at $t-1$ (log) & $(0.0491)$ & $(0.0518)$ & $(0.0502)$ & $(0.386)$ \\
& $(0.0722)$ & $(0.119)$ & $(0.0784)$ & $(0.438)$ \\
& $0.323 * * *$ & $0.319 * * *$ & 0.0526 & $1.819^{* * *}$ \\
& $(0.0778)$ & $(0.104)$ & $(0.115)$ & $(0.493)$
\end{tabular}


Table 9 continued

\begin{tabular}{lllll}
\hline & $(1)$ & $(2)$ & $(3)$ & $(4)$ \\
\hline Model & FE & TC sample & LDV & LD \\
Indiv. fixed effects & Yes & Yes & No & Yes \\
Year dummies & Yes & Yes & Yes & Yes \\
Control variables & Yes & Yes & Yes & Yes \\
Observations & 15,505 & 8309 & 6110 & 1032 \\
$R$-squared & 0.797 & 0.773 & 0.850 & 0.766 \\
\hline
\end{tabular}

Robust std. errors in parentheses. No telecommuting is the reference category. Control variables are the same as in Tables 4 and 5

$F E$ fixed effects, $T C$ telecommuting, $L D V$ lagged dependent variable, $L D$ long differences

$* * * p<0.01 ; * * p<0.05 ; * p<0.1$

\section{References}

Alonso W (1974) Location and land use: toward a general theory of land rent. Harvard University Press, Cambridge

Andreev P, Salomon I, Pliskin N (2010) Review: state of teleactivities. Transp Res C Emerg Technol 18(1):3-20. https://doi.org/10.1016/j.trc.2009.04.017

Angrist J, Pischke J (2008) Mostly harmless econometrics: an empiricist's companion. Princeton University Press, Princeton

Bernardino A (2017) Telecommuting: modelling the employer's and the employee's decision-making process. Routledge, London

Büchel F, Van Ham M (2003) Overeducation, regional labor markets, and spatial flexibility. J Urban Econ 53(3):482-493. https://doi.org/10.1016/S0094-1190(03)00008-1

Burger MJ, Meijers EJ (2016) Agglomerations and the rise of urban network externalities. Pap Reg Sci 95(1):5-15. https://doi.org/10.1111/pirs.12223

Burger MJ, Meijers EJ, Van Oort FG (2014) Multiple perspectives on functional coherence: heterogeneity and multiplexity in the randstad. Tijdschr Econ Soc Geogr 105(4):444-464. https://doi.org/10.1111/t esg. 12061

Cairncross F (1997) The death of distance: how the communication revolution is changing our lives. Harvard Business School Press, Boston

De Graaff T (2004) On the substitution and complementarity between telework and travel: a review and application. Research memorandum 16-2004, Vrije Universiteit Amsterdam. http://degree.ubvu.vu.n 1/repec/vua/wpaper/pdf/20040016.pdf

Glaeser EL, Kahn ME (2004) Sprawl and urban growth. In: Henderson JV, Thisse JF (eds) Handbook of regional and urban economics, vol 4. Elsevier, Amsterdam, pp 2481-2527. https://doi.org/10.1016/s 1574-0080(04)80013-0

Gronberg T, Reed W (1994) Estimating workers' marginal willingness to pay for job attributes using duration data. J Hum Resour 29(3):911-931. https://doi.org/10.2307/146258

Groot SPT, de Groot HLF, Smit MJ (2014) Regional wage differences in the Netherlands: micro evidence on agglomeration externalities. J Reg Sci 54(3):503-523. https://doi.org/10.1111/jors. 12070

Gubins S, Verhoef ET (2014) Dynamic bottleneck congestion and residential land use in the monocentric city. J Urban Econ 80:51-61. https://doi.org/10.1016/j.jue.2013.09.001

Isacsson G, Karlström A, Swärdh JE (2013) The value of commuting time in an empirical on-the-job search model an application based on moments from two samples. Appl Econ 45(19):2827-2837. https://do i.org/10.1080/00036846.2012.678981

Jiang Y (2008) The impact of telecommuting on the journey to work: a two-sample instrumental variables approach. Dissertation chapter, University of Maryland. http://drum.lib.umd.edu/bitstream/handle/19 03/8506/umi-umd-5557.pdf 
Kim SN, Mokhtarian PL, Ahn KH (2012) The Seoul of Alonso: new perspectives on telecommuting and residential location from South Korea. Urban Geogr 33(8):1163-1191. https://doi.org/10.2747/02723638.33.8.1163

Kim SN, Choo S, Mokhtarian PL (2015) Home-based telecommuting and intra-household interactions in work and non-work travel: a seemingly unrelated censored regression approach. Transp Res A Policy Pract 80:197-214. https://doi.org/10.1016/j.tra.2015.07.018

Kolko J (2012) Broadband and local growth. J Urban Econ 71(1):100-113. https://doi.org/10.1016/j.jue.2 011.07.004

Lund JR, Mokhtarian PL (1994) Telecommuting and residential location: theory and implications for commute travel in monocentric metropolis. Transportation research record 1463, pp 10-14. http://online pubs.trb.org/Onlinepubs/trr/1994/1463/1463-002.pdf

Mokhtarian PL, Salomon I, Choo S (2005) Measuring the measurable: why can't we agree on the number of telecommuters in the U.S.? Qual Quant 39(4):423-452. https://doi.org/10.1007/s11135-004-6790$\mathrm{Z}$

Moretti E (2011) Local labor markets. In: Ashenfelter OC, Card D (eds) Handbook of labor economics, vol 4. Elsevier, Amsterdam, pp 1237-1313. https://doi.org/10.1016/s0169-7218(11)02412-9

Muhammad S, Ottens HF, Ettema D, Jong T (2007) Telecommuting and residential locational preferences: A case study of the Netherlands. J Hous Built Environ 22(4):339-358. https://doi.org/10.1007/s1090 1-007-9088-3

Muhammad S, de Jong T, Ottens HFL (2008) Job accessibility under the influence of information and communication technologies, in the Netherlands. J Transp Geogr 16(3):203-216. https://doi.org/10.1 016/j.jtrangeo.2007.05.005

Muth RF (1969) Cities and housing. University of Chicago Press, Chicago

Naisbitt J (1994) The global paradox. William Morrow \& Co., New York

Nilles JM (1991) Telecommuting and urban sprawl: mitigator or inciter? Transportation 18(4):411-432. https://doi.org/10.1007/BF00186567

Rhee HJ (2008) Home-based telecommuting and commuting behavior. J Urban Econ 63(1):198-216. https:// doi.org/10.1016/j.jue.2007.01.007

Salomon I (1985) Telecommunications and travel: substitution or modified mobility? J Transp Econ Policy. https://doi.org/10.1080/09595238100185051

SCP (2016) Arbeidsaanbodpanel 1985 t/m 2014. https://doi.org/10.17026/dans-x8q-46p7

Toffler A (1980) The third wave. Bantam Books, New York

Van Ham M (2002) Job access, workplace mobility, and occupational achievement. Eburon, Delft

Van Ommeren J (1998) A test for randomly sampling using duration observations. Appl Econ Lett 5(4):243-246. https://doi.org/10.1080/135048598354906

Van Ommeren J, Fosgerau M (2009) Workers' marginal costs of commuting. J Urban Econ 65(1):38-47. https://doi.org/10.1016/j.jue.2008.08.001

Van Ommeren J, Van Den Berg GJ, Gorter C (2000) Estimating the marginal willingness to pay for commuting. J Reg Sci 40(3):541-563. https://doi.org/10.1111/0022-4146.00187

Van Wee B, Geurs KT, Chorus C (2013) Information, communication, travel behavior and accessibility. J Transp Land Use 6(3):1-16. https://doi.org/10.5198/jtlu.v6i3.282

Vermeulen W, Rouwendal J (2007) Housing supply and land use regulation in the Netherlands. SSRN Electr J. https://doi.org/10.2139/ssrn.1003955

Webber MM (1963) The post-city age. Daedalus 97(4):1091-1110. http://www.jstor.org/stable/20013413

Zhu P (2012) Are telecommuting and personal travel complements or substitutes? Ann Reg Sci 48(2):619-639. https://doi.org/10.1007/s00168-011-0460-6 